\section{Case Reports in Ophthalmology}

\title{
A Case of Proliferative Retinopathy Complicated with Tuberous Sclerosis Treated by Vitreous Surgery
}

\author{
Emika Nemoto Seita Morishita Mari Akashi Ryohsuke Kohmoto \\ Masanori Fukumoto Hiroyuki Suzuki Takatoshi Kobayashi \\ Teruyo Kida Jun Sugasawa Tsunehiko Ikeda \\ Department of Ophthalmology, Osaka Medical College, Takatsuki City, Japan
}

\section{Keywords}

Tuberous sclerosis $\cdot$ Retinal hamartoma $\cdot$ Proliferative retinopathy $\cdot$ Vitreous surgery

\begin{abstract}
We report a case of proliferative retinopathy complicated with retinal hamartoma in a tuberous sclerosis patient. This study involved a 16 -year-old female patient who was diagnosed as having tuberous sclerosis at birth. Ophthalmic examination revealed retinal hamartoma surrounding the optic disc in both eyes. Vitreous surgery involving a vitrectomy and resection of the proliferative membranes was performed for proliferative retinopathy in her right eye. Postoperative fundus findings showed improvement and decreased exudative changes. The proliferative and exudative changes appeared to be due to the retinal hamartoma, and vitreous surgery proved effective in this case.

(C) 2016 The Author(s) Published by S. Karger AG, Basel
\end{abstract}

\section{Introduction}

Tuberous sclerosis (TS) is a disease with an autosomal dominant pattern of inheritance characterized by hamartoma throughout the body, with 3 dominant features consisting of mental deficiency, epileptic seizures, and facial hemangiomas [1]. As an ophthalmological symptom, hamartomas are found in the retina and optic nerves of approximately $50 \%$ of the 


\section{Case Reports in Ophthalmology}

Case Rep Ophthalmol 2016;7:277-283

\begin{tabular}{l|l}
\hline DOI: $10.1159 / 000453391$ & ○ 2016 The Author(s). Published by S. Karger AG, Basel \\
\hline
\end{tabular} www.karger.com/cop

Nemoto et al.: A Case of Proliferative Retinopathy Complicated with Tuberous Sclerosis Treated by Vitreous Surgery

patients [2]. While the vast majority of hamartomas become calcified and do not require treatment, on rare occasions they increase, resulting in exudative changes. While treatment typically involves subjecting the hamartoma to laser photocoagulation, vitreous surgery may also be appropriate in cases complicated by exudative retinal detachment or vitreous hemorrhage [3-10]. However, and to the best of our knowledge, there have only been 6 reports of vitreous surgery being performed in cases of extensive proliferative retinopathy associated with TS [5-10]. Here, we report the case of a TS patient with advanced proliferative retinopathy accompanied by hamartoma that was successfully treated by vitreous surgery.

\section{Case Report}

A 16-year-old female presented who had previously been diagnosed with TS and subjected to medical treatment at approximately 1 -month after birth. Communication was difficult due to the patient's mental retardation. Around February 2013, the patient began displaying behavioral patterns indicating a visual disturbance, thus prompting a consultation with the patient's previous doctor. She was diagnosed as having hypermature cataract in her right eye, and subsequently underwent lensectomy in that eye for treatment. A postoperative funduscopic examination indicated proliferative retinopathy, and she was referred to the Department of Ophthalmology at Osaka Medical College in January 2014.

Upon initial examination, nothing peculiar was found with regard to the patient's medical and family history; however, she had facial hemangiofibroma distinctive of TS spread across both sides of her face from the nose to the cheeks (Fig. 1). It was impossible to measure visual acuity and intraocular pressure due to the patient's mental retardation. Anterior segment findings of her eyes revealed that a surgery had been performed on a hypermature cataract in the right eye by the previous physician that resulted in surgical aphakia in that eye. A posterior subcapsular cataract was observed in her left eye. Fundus findings revealed upper and lower peripapillary retinal hamartomas in the right eye, with subretinal exudative changes in the surrounding area; an extensive proliferative fibrous membrane was also observed along the vascular arcade, which exhibited proliferative retinopathy (Fig. 2a). Although visibility of the left-eye fundus was poor due to cataract, hamartomas could be observed in the peripapillary region, with prominent hard exudates in the surrounding area (Fig. 2b).

The clinical course consisted of vitreous surgery being performed under general anesthesia in the patient's right eye on February 28, 2014. During surgery, remarkable retinal folds due to the proliferative fibrous membranes were observed in the macular region (Fig. 3 ). After the core vitrectomy, the fibrous membranes were resected using a 25-gauge vitreous cutter. When necessary, vitreous scissors were used on the areas of persistent vitreoretinal adhesion. Whitened ghost retinal blood vessels were observed around the optic disc, whereupon we performed panretinal endophotocoagulation over 4 quadrants of the fundus. It was determined that extraction of the hamartomas would be difficult; therefore, endophotocoagulation was also directly performed on the hamartomas until the lesions turned white in color. Postoperatively, the hamartomas were only somewhat reduced, yet the exudative changes around the hamartoma were significantly decreased (Fig. 4). 


\section{Case Reports in Ophthalmology}

Case Rep Ophthalmol 2016;7:277-283

\begin{tabular}{l|l} 
DOI: $10.1159 / 000453391$ & ( 2016 The Author(s). Published by S. Karger AG, Basel
\end{tabular} www.karger.com/cop

Nemoto et al.: A Case of Proliferative Retinopathy Complicated with Tuberous Sclerosis Treated by Vitreous Surgery

\section{Discussion}

TS reportedly occurs at a rate of approximately 1 in 10,000 births, and approximately $60 \%$ of those cases are regarded as sporadic [1]. Recently, an increasing number of mild TS cases has been observed due to advancements in the testing techniques. Ophthalmological findings have shown that retinal hamartoma occurs in conjunction with TS in approximately $50 \%$ of TS cases, and that it usually occurs around the optic disc. Histologically, these are regarded as astrocytic hamartoma [2]. While symptomatic changes to the fundus due to a retinal hamartoma occur in comparatively few cases, there have been some reports of other changes, including subretinal hard exudates, macular edema, vitreous hemorrhage, and exudative retinal detachment [3-10]. This invasive tumorous lesion tends to be limited to the retinal nerve fiber layer (NFL), and when examined by spectral domain-optical coherence tomography (SD-OCT), NFLs are reportedly observed as dome-like ridges of high intensity $[11,12]$. In addition, it has also been reported that pathologically, myelin formation and gliosis are observed in this tumor [2]. In the present case, SD-OCT could not be performed due to the patient's mental retardation, yet hamartomas were observed in the vicinity of the optic disc.

As a treatment for ocular complications associated with TS in cases involving retinal exudative changes, direct laser photocoagulation has reportedly been effective $[2,13]$. There are very few reports of vitreous surgery being performed to treat ocular complications occurring in TS patients, and only a few previous reports of patients complicated with vitreous hemorrhage from tumors [5-10]. The majority of reports discussing the outcome of vitreous surgery for epiretinal membranes or traction retinal detachment brought about by hamartoma in the vicinity of the optic disc have involved cases of retinal and retinal pigment epithelium hamartoma $[14,15]$. To the best of our knowledge, there have been only 6 reports in which vitreous surgery was indicated for proliferative retinopathy with extensive fibrous membranes that arises secondarily to TS [5-10].

As a mechanism that gives rise to proliferative retinopathy, gliosis occurs due to the release of cytokines that promote intraocular inflammation, cell proliferation, and tissue remodeling. In the present case, despite the absence of any obvious retinal detachment, it is possible that some growth trigger or increased vascular permeability accompanying hamartoma led to the proliferative retinopathy. In addition, it can be theorized that as a result of performing vitreous surgery in this case, removal of the inflammatory cytokines in addition to the removal of the proliferative tissue led to the alleviation of the retinal pathological lesions. It is also possible that the endophotocoagulation performed directly on the hamartoma was effective.

In conclusion, since a hamartoma that occurs in conjunction with TS can cause proliferative retinopathy, as in the case reported here, we believe that close follow-up observation is necessary, including that of the patient's fellow eye.

\section{Acknowledgements}

The authors wish to thank John Bush for editing the manuscript. 
Case Reports in
Ophthalmology

Case Rep Ophthalmol 2016;7:277-283

DOI: 10.1159/000453391

C 2016 The Author(s). Published by S. Karger AG, Basel www.karger.com/cop

Nemoto et al.: A Case of Proliferative Retinopathy Complicated with Tuberous Sclerosis Treated by Vitreous Surgery

Statement of Ethics

This case study was approved by the Ethics Committee of Osaka Medical College.

\section{Disclosure Statement}

There are no conflicts of interest to report for all authors.

\section{References}

1 DiMario FJ Jr, Sahin M, Ebrahimi-Fakhari D: Tuberous sclerosis complex. Pediatr Clin North Am 2015;62:633-648.

2 Mennel S, Meyer CH, Peter S, Schmidt JC, Kroll P: Current treatment modalities for exudative retinal hamartomas secondary to tuberous sclerosis: review of the literature. Acta Ophthalmol Scand 2007;85:127-132.

-3 Veronese C, Pichi F, Guidi SG, Shields CL, Ciardella A: Cystoid changes within astrocytic hamartomas of the retina in tuberous sclerosis. Retin Cases Brief Rep 2011;5:113-116.

4 Lonngi M, Gold AS, Murray TG: Combined bevacizumab and triamcinolone acetonide injections for macular edema in a patient with astrocytic hamartomas and tuberous sclerosis. Ophthalmic Surg Lasers Imaging Retina 2013;44:85-90.

5 Wang CL, Brucker AJ: Vitreous hemorrhage secondary to juxtapapillary vascular hamartoma of the retina. Retina 1984;4:44-47.

-6 Kroll AJ, Ricker DP, Robb RM, Albert DM: Vitreous hemorrhage complicating retinal astrocytic hamartoma. Surv Ophthalmol 1981;26:31-38.

7 Inoue M, Hirakarta A, Iizuka N, Futagami S, Hida T: Tractional macular detachment associated with optic disc astrocytic hamartoma. Acta Ophthalmol 2009;87:239-240.

-8 Nakayama M, Keino H, Hirakata A, Okada AA, Terado Y: Exudative retinal astrocytic hamartoma diagnosed and treated with pars plana vitrectomy and intravitreal bevacizumab. Eye (Lond) 2012;26:1272-1273.

99 Saito W, Kase S, Ohgami K, Mori S, Ohno S: Intravitreal anti-vascular endothelial growth factor therapy with bevacizumab for tuberous sclerosis with macular oedema. Acta Ophthalmol 2010;88:377-380

10 Tomida M, Mitamura Y, Katome T, Eguchi H, Naito T, Harada T: Aggressive retinal astrocytoma associated with tuberous sclerosis. Clin Ophthalmol 2012;6:715-720.

11 Zhang P, Sun D, Zhu J, Li J, Wang Y: Image features of retinal astrocytic hamartoma in a patient with tuberous sclerosis complex. Eye Sci 2014;29:223-226.

12 Goel N, Pangtey B, Bhushan G, Raina UK, Ghosh B: Spectral-domain optical coherence tomography of astrocytic hamartomas in tuberous sclerosis. Int Ophthalmol 2012;32:491-493.

13 Bloom SM, Mahl CF: Photocoagulation for serous detachment of the macula secondary to retinal astrocytoma. Retina 1991;11:416-422.

14 Cohn AD, Quiram PA, Drenser KA, Trese MT, Capone A Jr: Surgical outcomes of epiretinal membranes associated with combined hamartoma of the retina and retinal pigment epithelium. Retina 2009;29:825-830.

15 McDonald HR, Abrams GW, Burke JM, Neuwirth J: Clinicopathologic results of vitreous surgery for epiretinal membranes in patients with combined retinal and retinal pigment epithelial hamartomas. Am J Ophthalmol 1985;100:806-813. 
Case Reports in
Ophthalmology Case Rep Ophthalmol 2016;7:277-283 DOI: $10.1159 / 000453391$ (C) 2016 The Author(s). Published by S. Karger AG, Basel www.karger.com/cop

Nemoto et al.: A Case of Proliferative Retinopathy Complicated with Tuberous Sclerosis Treated by Vitreous Surgery

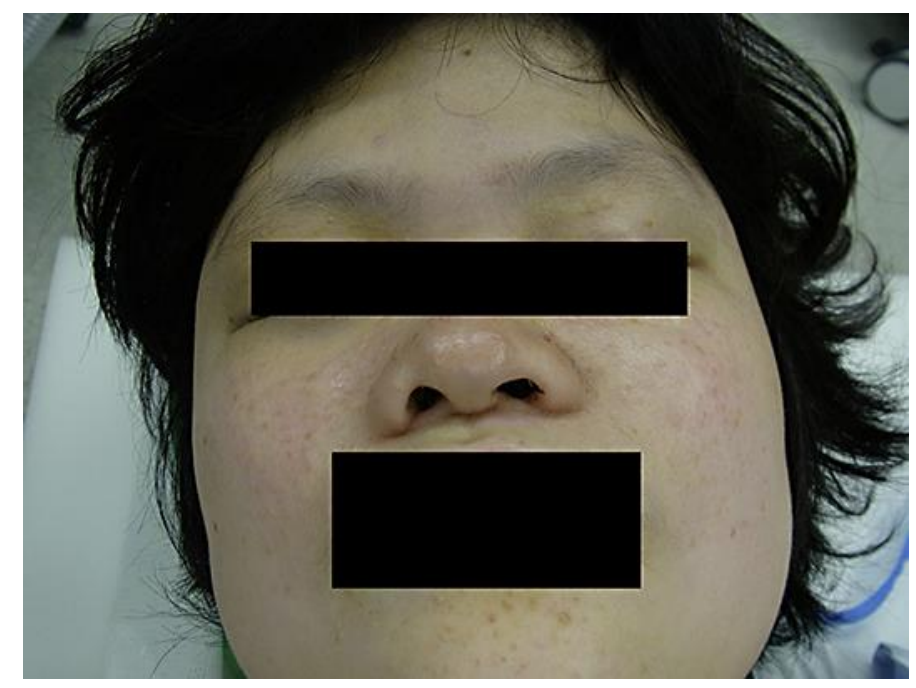

Fig. 1. Photograph of facial skin lesion in a female patient with proliferative retinopathy complicated with tuberous sclerosis (TS). Facial hemangiofibroma distinctive of TS can be seen spread across both sides of the face from the nose to the cheeks. 


\section{Case Reports in Ophthalmology}

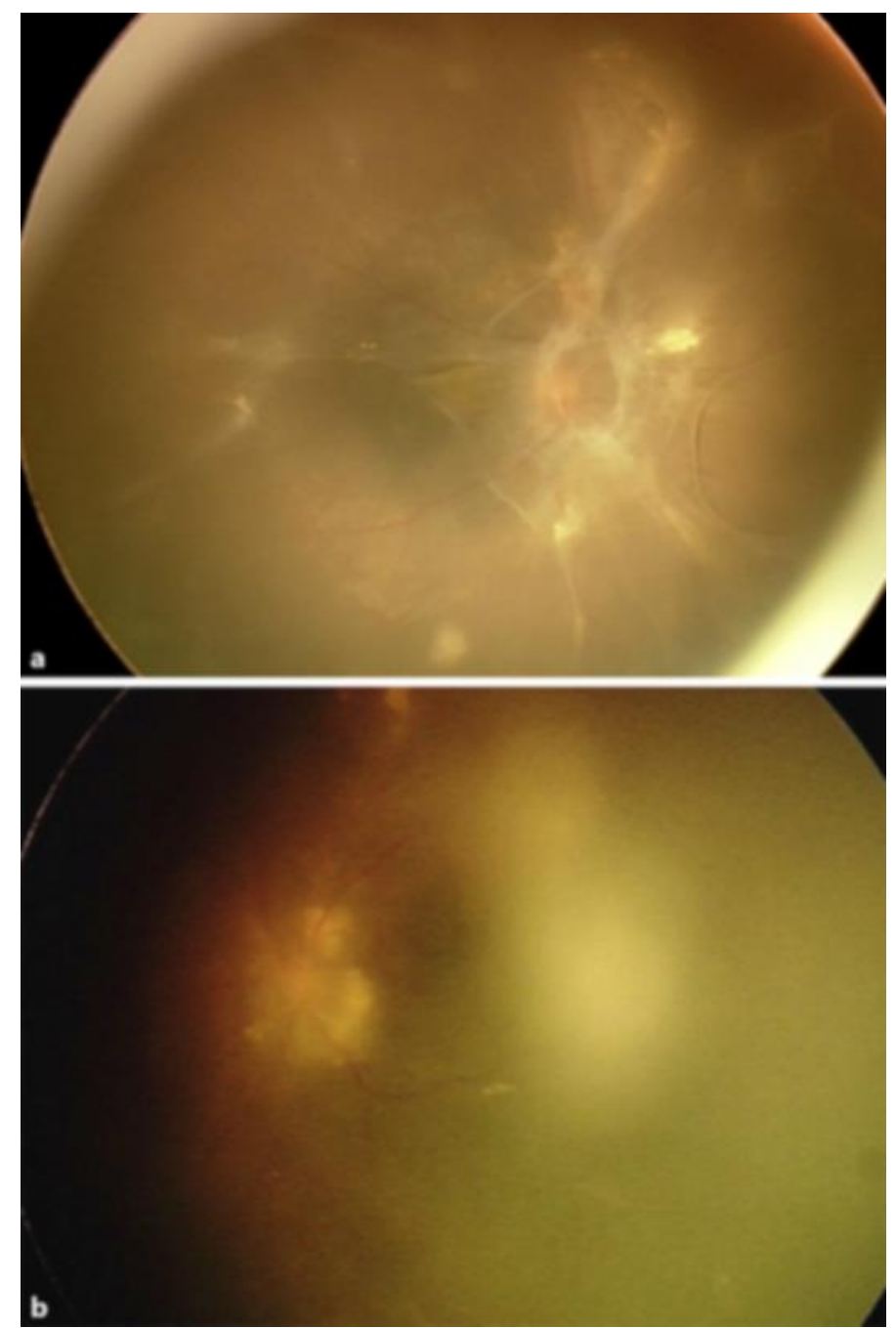

Fig. 2. Preoperative fundus photographs. a Right eye. b Left eye. A peripapillary retinal hamartoma accompanied by subretinal exudate can be seen in both eyes. Extensive proliferative fibrous membrane can also be observed along the vascular arcade in the patient's right eye.

Nemoto et al.: A Case of Proliferative Retinopathy Complicated with Tuberous Sclerosis Treated by Vitreous Surgery 


\section{Case Reports in \\ Ophthalmology}

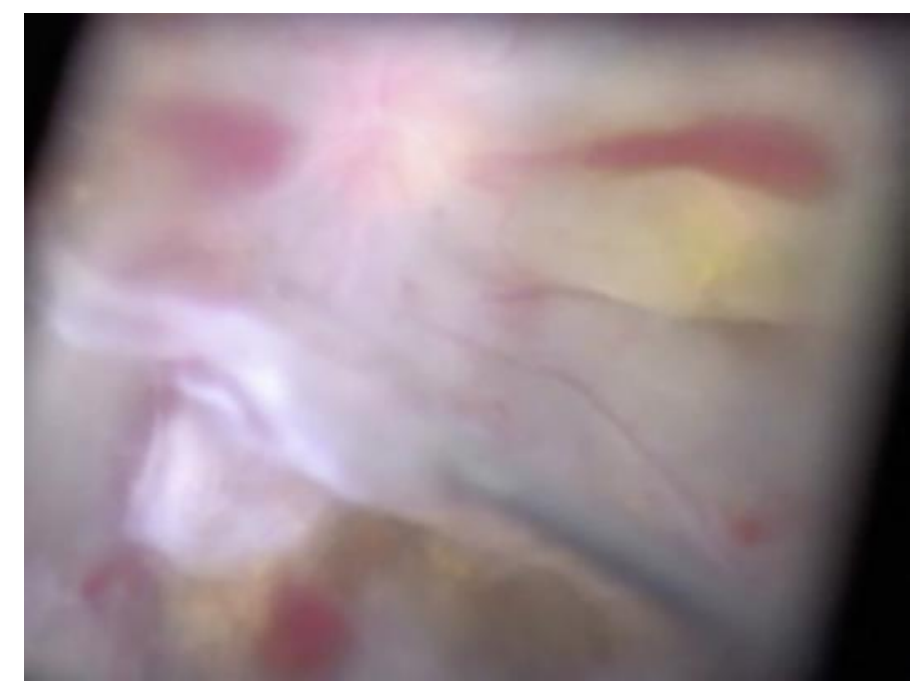

Fig. 3. Image showing the intraoperative findings of the patient's right eye. Remarkable retinal folds due to the proliferative fibrous membranes can be seen in the macular region.

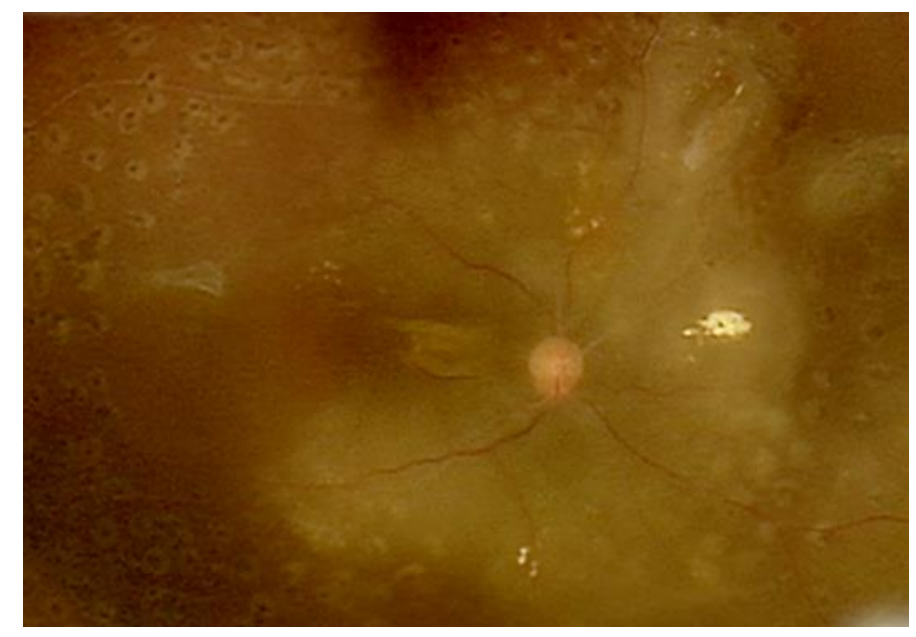

Fig. 4. Postoperative fundus photograph of the patient's right eye. After surgery, the hamartoma was only somewhat reduced, while the exudative changes around the hamartoma were significantly decreased. 